Article

\title{
Novel Mathematical Method to Obtain the Optimum Speed and Fuel Reduction in Heavy Diesel Trucks
}

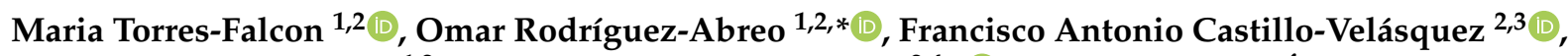 \\ Alejandro Flores-Rangel ${ }^{1,2}$, Juvenal Rodríguez-Reséndiz ${ }^{2,4, *}$ and José Manuel Álvarez-Alvarado 4 (i) \\ 1 Industrial Technologies Division, Universidad Politécnica de Querétaro, Querétaro 76240, Mexico; \\ consuelo.torres@upq.mx (M.T.-F.); alejandro.flores@upq.edu.mx (A.F.-R.) \\ 2 Red de Investigación OAC Optimización, Automatización y Control, Querétaro 76240, Mexico; \\ francisco.castillo@upq.mx \\ 3 Information Technology Division, Universidad Politécnica de Querétaro, Querétaro 76240, Mexico \\ 4 Facultad de Ingeniería, Universidad Autónoma de Querétaro, Querétaro 76010, Mexico; jmalvarez@uaq.mx \\ * Correspondence: omar.rodriguez@upq.edu.mx (O.R.-A.); juvenal@uaq.edu.mx (J.R.-R.)
}

check for updates

Citation: Torres-Falcon, M.;

Rodríguez-Abreo, O.;

Castillo-Velásquez, F.A.;

Flores-Rangel, A.;

Rodríguez-Reséndiz, J.;

Álvarez-Alvarado, J.M. Novel

Mathematical Method to Obtain the Optimum Speed and Fuel Reduction in Heavy Diesel Trucks. Energies 2021 14, 8121. https://doi.org/10.3390/ en14238121

Academic Editor: Marina K. Kousoulidou

Received: 1 November 2021

Accepted: 26 November 2021

Published: 3 December 2021

Publisher's Note: MDPI stays neutral with regard to jurisdictional claims in published maps and institutional affiliations.

Copyright: (c) 2021 by the authors. Licensee MDPI, Basel, Switzerland. This article is an open access article distributed under the terms and conditions of the Creative Commons Attribution (CC BY) license (https:// creativecommons.org/licenses/by/ $4.0 /)$.
Abstract: In Mexico and many parts of the world, land cargo transport units (UTTC) operate at high speeds, causing accidents, increased fuel costs, and high levels of polluting emissions in the atmosphere. The speed in road driving, by the carriers, has been a factor little studied; however, it causes serious damage. This problem is reflected in accidents, road damage, low efficiency in the life of the engine and tires, low fuel efficiency, and high polluting emissions, among others. The official Mexican standard NOM-012-SCT-2-2017 on the weight and maximum dimensions with which motor transport vehicles can circulate, which travel through the general communication routes of the federal jurisdiction, establishes the speed limit at the one to be driven by an operator. Because of the new reality, the uses and customs of truck operators have been affected, mainly in their operating expenses. In this work, a mathematical model is presented with which the optimum driving speed of a UTTC is obtained. The speed is obtained employing the equality between the forces required to move the motor unit and the force that the tractor has available. The required forces considered are the force on the slope, the aerodynamic force, and the friction force, and the force available was considered the engine torque. This mathematical method was tested in seven routes in Mexico, obtaining significant savings of fuel above $10 \%$. However, the best performance route possesses $65 \%$ flat terrain and 35\% hillocks without mountainous terrain, regular type of highway, and a load of $20,000 \mathrm{~kg}$, where the savings increase up to $16.44 \%$.

Keywords: fuel savings; mathematical model; transport; driver conduction; road transport; emissions reduction; fuel efficiency

\section{Introduction}

Inefficient driving by truck drivers is very common in Mexico and in many parts of the world. China, for example, proposes motivational techniques for its cargo truck operators based on financial rewards. They presented that there are effects such as the personality of the operator, the conditions and/or external stimuli, traffic characteristics, or conditions of the vehicle that intervene in saving fuel. In this country, they proposed a control technique based on eco-driving. They obtained, with this implementation, savings of up to $10 \%$ [1].

In another investigation, statistical tools were applied to determine five behaviors of operating the motor unit, such as: acceleration levels, ups and downs, and idle times. Position, speed, and fuel consumption were taken into consideration. The records were 199 cargo units. The data were collected onboard the truck. The methodology consisted of applying a fixed-effects model based on panel data to estimate the effects of inefficient driving behaviors on fuel efficiency and the potential for fuel savings by improving these 
behaviors. They experienced excessive idle times and deceleration that was too rapid, which caused a considerable increase in fuel consumption [2].

The authors of [3] performed their study in a company that transports wood, and in the behavior of the drivers, their average speed, braking, and idling were identified as key factors that affect diesel performance. The study demonstrated that the efficiency of the driver increases when they are trying to cover long distances with low fuel, and it was notable that the incentive scheme promotes to improve the performance of the inefficient drivers.

The contribution of [4] is related to safe, efficient, and clean transport by controlling speed on long and steep slopes. The speed optimization using the Pontryagin iterative maximum principle algorithm is proposed. The authors performed a simulation-based evaluation of the proposal model, finding that the maximum temperature of the brake drums is reduced according to the speed control system, obtaining a safe temperature work and a reduction of fuel consumption of $15.50 \%$.

Authors from [5] mentioned that the climatic effects can affect the performance of the cargo drive unit, as well as the behavior of the driver. In this investigation, the driver was subjected during the trip on rainy days. They used the highway information database, and a comparative analysis was made of the behavior of the operator in heavy and light rain conditions, using coincident trips. Those were defined as trips with the same driver, the exact vehicle, and the same routes traversed. The statistical analysis they provided demostrated significant differences when the driver operated in clear and rainy weather conditions. The study revealed a low probability of raising the speed limit on roads under extreme climatic conditions. The results were that the behavior and conduct of the tractor operator significantly affect driving.

The article [6] describes simulations to investigate how the length of the control horizon influences potential energy savings. The simulation demonstrated up to $7 \%$ energy savings without increasing travel time or deviating from the regular driving route. The article shows a simulation of saving energy when the vehicle is optimally controlled. The simulation demonstrated up to $7.00 \%$ energy saving without increasing travel time or deviating from the regular driving route. Moreover, a horizon length of $500 \mathrm{~m}$ can save significant energy by using the proposal controller. This model performs well in a minimum of $1000 \mathrm{~m}$ horizon length to save energy. Works such as that presented in [7] also work with mathematical models for saving fuel used in fuel stations.

Recent studies show that using different alternative fuel blends improves the reduction in emissions without sacrificing engine performance [8-10]. For example, the work [11] uses an alternative fuel based on Silkworm Oil Methyl Ester (SWOME) that has a better performance and, with pre and post-combustion control, reduces $\mathrm{CO}_{2}$ emissions by up to $85 \%$. In [12], the effects of advanced injection timing combined with dual fuel mode on the overall performance of the diesel engine are studied. For this, multiple experimental tests were carried out with blends of waste oil methyl ester (WOME), demonstrating that the emissions can be reduced while increasing engine performance. In the same line of research, the effect of using the pre-mixed charge of biogas enriched with hydrogen in different types of engines has also been studied. In [13], a change in emissions according to the mixture used and the operating conditions was shown.

A different approach is the use of intelligent methods, and some work is focused on the prediction and modeling of emissions $[14,15]$. On the other hand, smart methods are used to improve engine performance through speed control [16]. For example, in [17], the details of the importance of eco-driving, emphasizing speed control, acceleration, deceleration, choice of route, and idling are studied. Likewise, it considers that the driver is a vital part, which is generally overlooked. The article reviews the application of devices and training programs in the vehicle, quantitative eco-driving patterns that can be integrated into the hardware of the vehicle to generate higher performance. Another example is where the authors of the research paper [18] used a multiscale-grid-based stacked bidirectional for 
predicting traffic speeds of urban expressways or the work [19] where the authors present a fuzzy system to save fuel based on the use of generators with lithium-ion batteries.

The research of [20] describes the use of autoregressive statistical models in conjunction with neural networks to predict the speed of a truck. They propose using neural networks to predict the speed of transport of goods, where the driver can make decisions about the route to follow. This method only proposes the prediction of the speed and the possible route to drive. Continuing in Croatia, tools such as convolutional neural networks (CNN) have been implemented, occupying speeds in periods of each week as input data. They propose a model considering an input and output layer with four convolutional layers. After performing the data analysis, they were able to predict the quality of traffic at the busiest intersections in the city of Zagreb [21].

The literature shows relevant advantages in saving energy in trucks. However, the challenge is to propose new techniques to prevent speed violation rates for road vehicles [22]. Actually, the production of new heavy trucks that reach high limits is being carried out. These vehicles with no optimal speed control can cause severe loss of life, materials, or property. Hence, it is important to propose cheap, practical, and non-invasive technologies [23].

In this context, a systematic review of the literature has been presented to discover and evaluate the different approaches to vehicle speed assistance for road vehicles in intelligent transport systems. On the part of the carriers, the speed in road driving has been a little-studied factor; however, severe damage is caused by not keeping it under control.

The official Mexican standard NOM-012-SCT-2-2017 on the weight and maximum dimensions with which transport vehicles can circulate establishes the speed limit an operator must drive. However, this is rarely respected [24]. In Mexico, this problem is reflected in accidents, damage to roads, low efficiency in the life of the engine, tires, low fuel efficiency, and increasing $\mathrm{CO}_{2}$ emissions, among others [25]. In this context, the share of the most common vehicle classes from 2009 to date are those corresponding to the three-axle truck and two-axle semi-trailer (T3S2) and the three-axle truck, two-axle semi-trailer, and trailer three-axle (T3S2R4). On the other hand, accidents on the road are minimized by driving at maximum speed and not traveling the road at high speeds. The participation of this type of truck at the national level is $63 \%$ of the total vehicular cargo movement in Mexico [25].

The studies mentioned above show that engine performance and emissions are a multivariate problem. Speed is a critical factor in performance, emissions, and safety. However, the calculation of the optimal speed is a complex multi-factor problem that must be updated to different road and vehicle conditions. For this reason, this work presents a mathematical model in which the optimal driving speed of a land cargo transport unit (UTTC) is obtained for units type T3S2 and T3S2R. The estimation of the optimal driving speed must consider the equality between the force available to the vehicle and the force it requires to travel a road. This work focuses on heavy truck operators, where the driver is an important factor that is often overlooked. Thoughtful and analytical driving represents a relatively low-cost measure to reduce fuel consumption significantly. The determining factor in achieving these objectives is to drive at the optimum speed, where the required power $\left(P_{r}\right)$ of the road and the available power $\left(P_{a}\right)$ in the truck are equated. The variables to consider are like a tailored suit per truck and route. The novelty of the work is that it does not generate extra costs for the transport company because the unit must only be driven at the maximum calculated speed. This method was tested in seven runs, obtaining significant fuel savings of up to $10.09 \%$.

The rest of the work is organized as follows. In Section 2, the methodology is explained. Later, Section 3 presents the most relevant results in seven route tests, which were carried out with the calculated speeds, obtaining significant average savings for the transport companies of $10.09 \%$. Finally, in Section 4, the conclusions are presented. 


\section{Methodological Approach}

The methodology consists in obtaining the optimum driving speed of a UTTC through the forces that oppose the movement and the force which the UTTC has available. Furthermore, the slope, ground resistance, and aerodynamic resistance were considered in the performance of the model [26-28]. The forces are calculated by route and by type of truck. These two calculations are equalized, and the maximum speed is obtained. The general procedure for obtaining the optimal speed is shown in Figure 1.

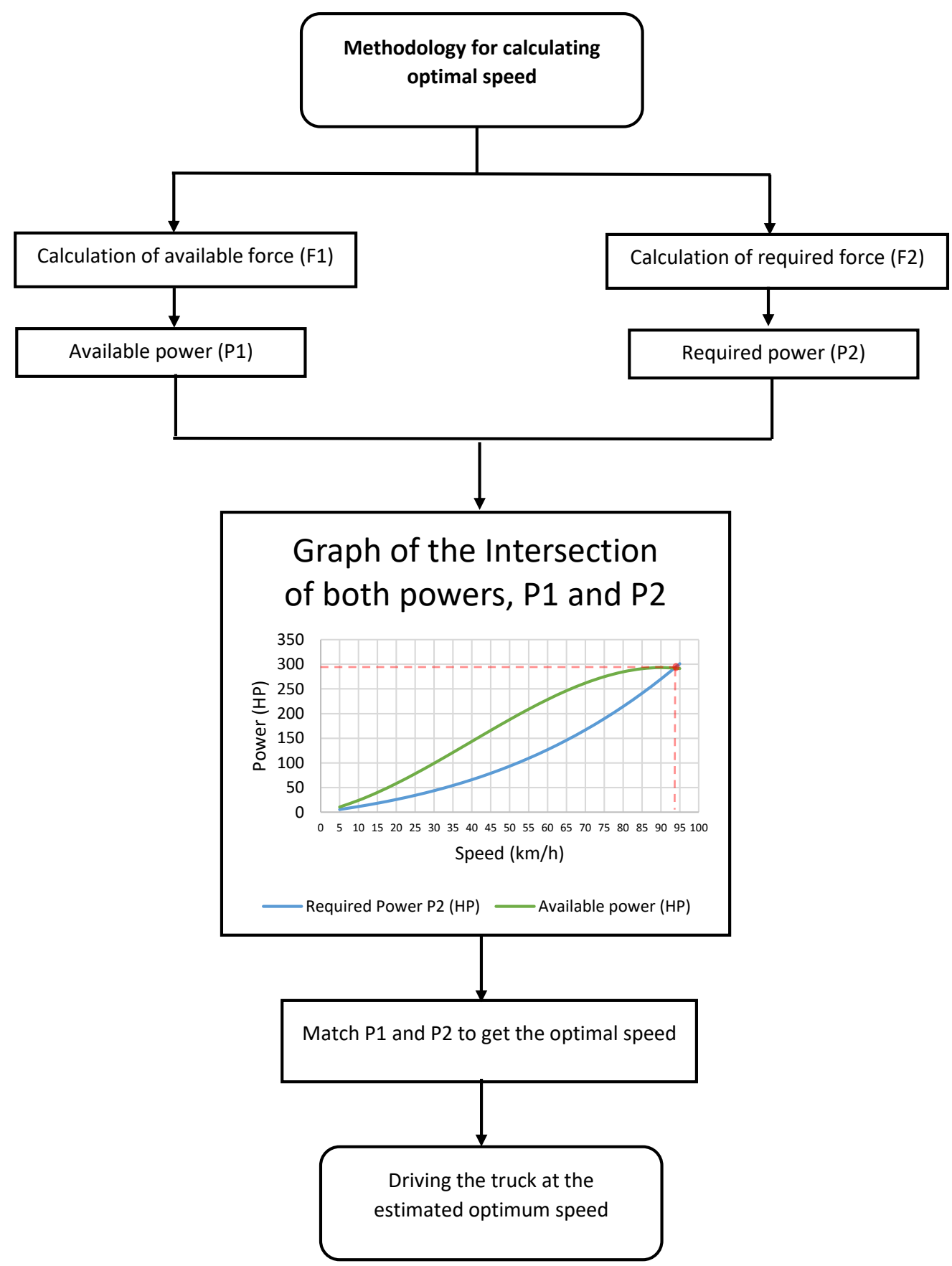

Figure 1. General procedure for obtaining the optimal speed. 


\subsection{Calculation of Available Force}

The equation to calculate the motor available force [25] is given by:

$$
F 1=M T_{r}
$$

where:

$M=$ Equation of engine torque $(\mathrm{Nm})$;

$T=$ Differential (axle ratio)/tire diameter $(\mathrm{m})$;

$r=$ Engine performance.

The torque, or torsional torque curve, measures the force exerted at the engine output in $\mathrm{Nm}$. We proceed to adjust the torque curve through the equation:

$$
M=M_{0}+M_{1} R+M_{2} R^{2}
$$

The previous equation represents the equation of polynomial regression fit of the motor torque curve of the UTTC [25], with $M_{0}, M_{1}$, and $M_{2}$, polynomial regression coefficients. These constants were obtained from the non-linear relationship between the independent variable $R$, which is the revolutions per minute of the engine (RPM), and the dependent variable $M$. To perform the proposal model, the torque curves of caterpillar and detroid diesel engine were considered according to $[29,30]$. The relationship was modeled with a second-order polynomial by solving a $3 \times 3$ system of equations. $R$, was defined as shown in Equation (3):

$$
R=2.57 T V
$$

where $T$ can be calculated according to Equation (4):

$$
T=\frac{(\text { differential }) \times(\text { axle ratio })}{\text { tire diameter }}
$$

where differential and axle ratio are dimensionless variables and tire diameter is given in $\mathrm{cm}$.

\subsection{Calculation of Required Force}

The powertrain of the vehicle (engine, transmission, differential, axles, and wheels) is designed to convert engine torque into useful tractive force from the tires to the pavement. When this force is greater than the sum of the forces that act against the movement of the vehicle, it accelerates in the direction of the road [25]. The tractive force greater than the forces that oppose the vehicle, accelerating it, can be expressed as in Equation (5):

$$
F 2=\text { Frod }+ \text { Faerod }+ \text { Fpend }+m a
$$

where $F 2$ is the tractive force available in tires, Faerod is the aerodynamic drag force, Frod is the rolling resistance force, and Fpend is the resistance force to slope.

The mathematical model considers that the tractive force is equal to the sum of the forces that oppose the movement of the vehicle [26]. The acceleration (a) must have small changes for the correct model application, implying that it can be neglected. Therefore, Equation (5) can be rewritten as follows:

$$
F 2=\text { Frod }+ \text { Faerod }+ \text { Fpend }
$$

The sum of the aerodynamic drag forces are a function of the air density $\left(C_{2}\right)$, the coefficient of aerodynamic resistance $\left(C_{d}\right)$, the frontal area of the vehicle $(A)$, and the speed of the unit $(V)$. 


$$
\text { Faerod }=C_{2} C_{d} A V^{2}
$$

where $C_{2}$ is the air density in $\mathrm{kg} / \mathrm{m}^{3}$ with a constant value of $0.04449, A$ is the front area of the vehicle in $\mathrm{m}^{2}, V$ is the unit velocity in $\mathrm{m} / \mathrm{s}$, and $C_{d}$ is the aerodynamic coefficient with a constant value of 0.7 . Rolling resistance force is the sum of the forces required to overcome frictional resistance in tires. The force required to overcome friction resistance can be expressed as the index of friction to the floor, the weight of the vehicle, the aerodynamic and static coefficients, and the speed [25,31,32].

$$
\text { Frod }=\left(C_{8} m+C_{v} m V\right) p
$$

where $C_{8}$ is the static friction coefficient with a constant value of $0.05025, C_{v}$ is the dynamic friction coefficient with a value of 0.00051 . Finally, $p$ is the floor roughness index which can be three different values according to the state of the road:

- $\quad p=1$ for good road;

- $\quad p=1.5$ for regular road;

- $\quad p=2$ for bad road.

The components of the gravitational force affect the weight of the vehicle.

$$
\text { Fpend }=g m \sin (\alpha)
$$

where the $m$ is the unit mass given in $\mathrm{kg} ; \mathrm{g}$ is the acceleration of gravity in $\mathrm{m} / \mathrm{s}^{2}$, and $\alpha$ is the inclination angle. Once the required forces are calculated, it is converted to the required power hp.

The model considers the possible types of terrain: flat, hill, mountain, and road; good, regular, and bad. The required power is calculated based on the route of the truck, so it is possible to calculate it for any combination. Figure 2 shows three possible combinations.

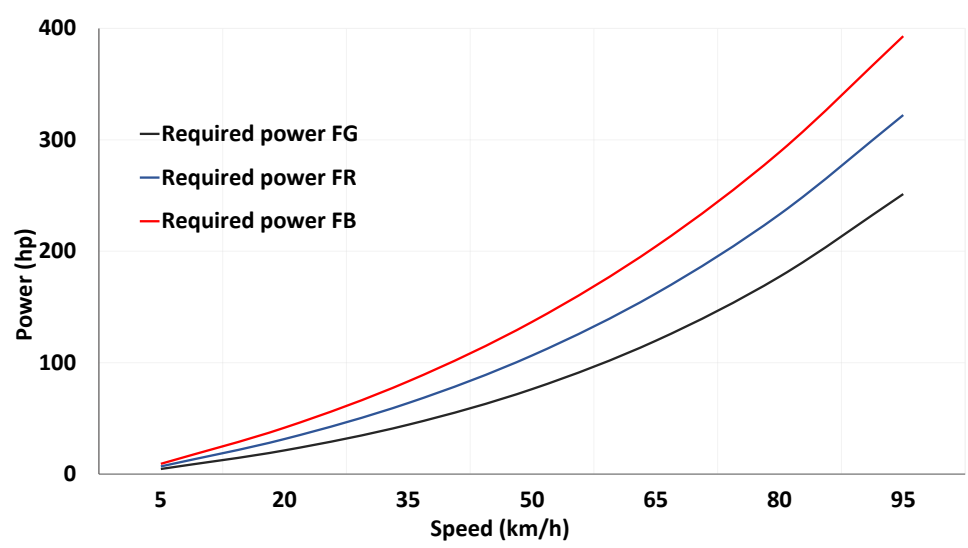

Figure 2. Required power curves given in hp. The land is Flat (F) highway: Good (G), Regular (R), and $\mathrm{Bad}(\mathrm{B})$.

\subsection{Optimal Speed: Match of the Available and Required Forces}

Now, with the intersection of the curve of the available power and the required power, the maximum speed per power is found, that is: at the point where $P_{a}=P_{r}$, we have the maximum speed per power for each angle of inclination (flat, hilly, and mountainous terrain). Each point is found by solving simultaneous equations as follows: 


$$
\begin{aligned}
& V^{2}\left(\left(C_{1} M_{2} T^{3} r\right)-\left(C_{2} C_{d} A\right)\right) \\
& +V\left(\left(2.57 M_{1} T^{2} r\right)-\left(C_{v} m p\right)\right) \\
& +\left(M_{0} T r-C_{8} m p-9.81 m \sin \alpha\right)=0
\end{aligned}
$$

With:

$$
\begin{aligned}
& C_{1}=\text { constant from mathematical calculation } \\
& C_{2}=\text { air density } \mathrm{kg} / \mathrm{m}^{3}=0.04449 \mathrm{~kg} / \mathrm{m}^{3} \\
& C_{v}=\text { dynamic friction coefficient }=0.00051 \\
& C_{d}=\text { aerodynamic coefficient }=0.9
\end{aligned}
$$

Therefore,the velocity is equal to the optimal speed $\left(\mathrm{S}_{\mathrm{o}}\right)$ calculated by the intersection of the available power and the required power, which is $\mathrm{V}=\mathrm{S}_{\mathrm{o}}$ and can be calculated as a simple quadratic equation.

The intersection is made with the curve of the available power while normally considering the change of the last gear of the transmission box, the curve of the required power that corresponds to the type of terrain, and the type of road of the route of the truck.

Figure 3 presents an example of the intersection of the curve of the available power of the 14th speed with three curves of the required power of the combinations for flat terrain with the typical road: Good (G), Regular (R), and Bad (B).

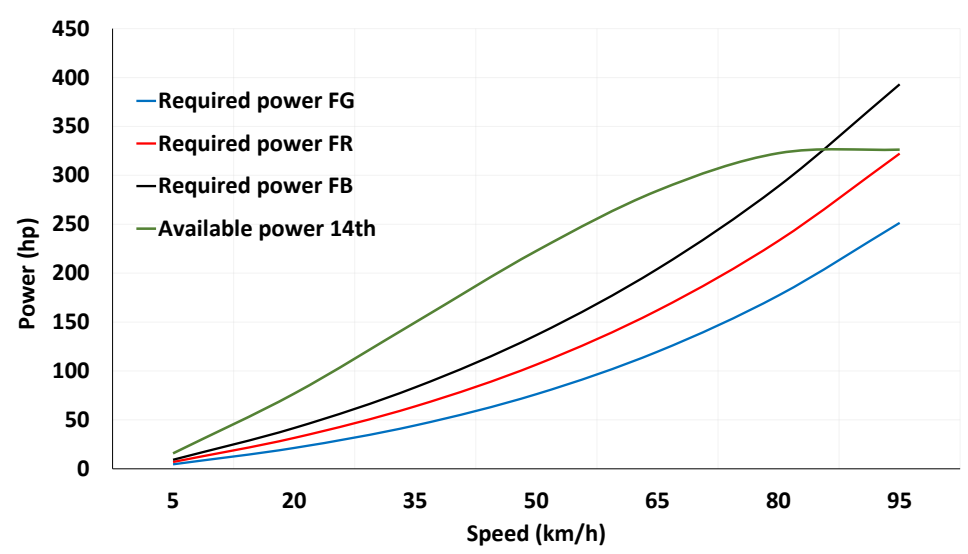

Figure 3. Intersections of the velocity curve of the available power at 14th speed, with the speed curves of the required power terrain: Flat (F) Road: Good (G), Regular (R) and Bad (B).

Normally, the maximum driving speed is obtained with the intersection of the curve of the representative power required of the route.

The corresponding expression for calculating fuel efficiency [25] is show in Equation (11):

$$
P_{e}=\frac{V}{(0.454)\left(P_{r}\right)(S C)}
$$

and $P_{r}$ is the required power obtained by Equation (12):

$$
P_{r}=\left(C_{8} m+C_{v} m V\right) p+\left(C_{2} C_{d} A V^{2}\right)+(m g \sin (\alpha))
$$

using an specific consumption of 0.33 . 


\section{Results}

The cargo trucks most used in Mexico are the T3S2 single and T3S2R4 full. These two models transported more than $68 \%$ of total cargo in 2019. In the same year, the two types of units accounted for $84 \%$ of the total value of the cargo. For this reason, units of these classes were considered in the fieldwork. Fieldwork was carried out on seven routes nationwide, with different transport companies of onboard vehicles type T3S2 (single) and T3S2R4 (full). The average maximum speed obtained was provided to each UTTC operator. This speed was obtained graphically as explained in the methodology. It was verified in person that the transport unit has been operated according to the maximum speed calculated by the model. The standard 14-speed gearboxes have different axle ratios as shown in Table 1.

Table 1. Axle ratio for standard 14-speed gearboxes.

\begin{tabular}{ccccccccccccccc}
\hline Speeds & 1st & 2nd & 3rd & 4th & 5th & 6th & 7th & 8th & 9th & 10th & 11th & 12th & 13th & 14th \\
\hline Axle ratio & 12.35 & 10.41 & 7.09 & 5.98 & 4.19 & 3.59 & 2.77 & 2.33 & 1.97 & 1.66 & 1.4 & 1.18 & 1 & 0.84 \\
\hline $\mathrm{T}$ & 107.1 & 90.3 & 61.5 & 51.9 & 36.3 & 31.1 & 24 & 20.2 & 17.1 & 14.4 & 12.1 & 10.2 & 8.7 & 7.3 \\
\hline
\end{tabular}

Then, it is necessary that for each axis relationship there will be a specific T. If we vary $\mathrm{V}$ from 5 to $100 \mathrm{~km} / \mathrm{h}$ for the first speed, with $\mathrm{T}=107.1$, the curve for the first speed is generated, obtaining the available force.

In the same range with $\mathrm{T}=90.3$, the curve for the second speed is generated, obtaining the corresponding available force. This process continues until the 14th gear. Subsequently, force is converted to power in hp. See Figure 4 with the last three speed curves, corresponding to gears 12,13 , and 14 , for a particular engine.

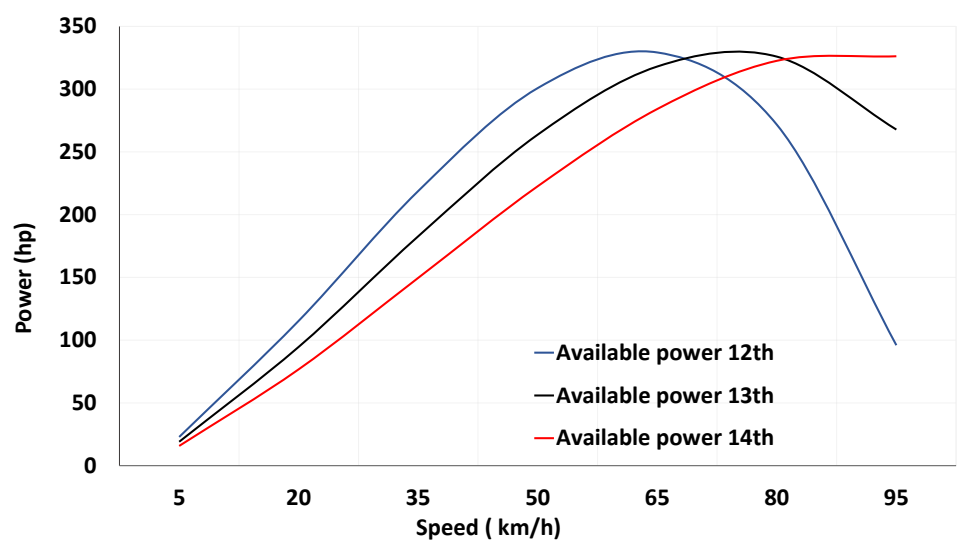

Figure 4. Speed curves corresponding to the available force of a motor and a SPICER gearbox for the three last speeds.

The procedure consisting of the unit would operate according to the speed calculated by the model. At the end of the tour, the performance normally observed by the operator was compared with the performance obtained in fieldwork. Using the theoretical model, the average fuel efficiency $(\mathrm{km} / \mathrm{L})$ was estimated for different scenarios and routes. The field work consisted of seven tours nationwide.

The first route was from Nuevo Laredo-Tamahulipas to Querétaro-Querétaro. The run was carried out considering the speed calculated with the model, obtaining a saving of $7.14 \%$, with the performance of $2.87 \mathrm{~km} / \mathrm{L}$, compared to the $2.6 \mathrm{~km} / \mathrm{L}$ of the truck operator. However, the calculation considered a good road type and a hilly terrain type. Most of the terrain has no slopes, so fuel efficiency tends to be high. In Figure 5, the optimum driving speed of $85 \mathrm{~km} / \mathrm{h}$ is shown. It was obtained from the equality of the powers required and available. It was considered that on average, the driver drove steadily in 12th gear. In the calculation, the time of hilly terrain and type of good road were assumed. 


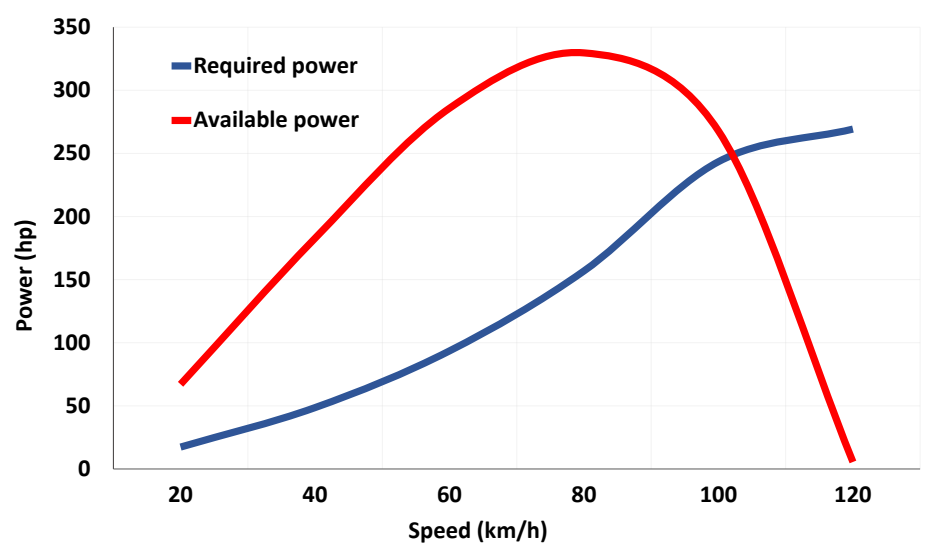

Figure 5. Route 1: Nuevo Laredo-Tamahulipas to Querétaro-Querétaro. Intersection of the curve of the available power of the 12th speed, and the curve of the required power of the hilly terrain and good road with $m=35,000 \mathrm{~kg}$.

The second route was from Coyuca-Puebla to Lagunas-Oaxaca. The run was carried out considering the speed calculated with the model of up to $75 \mathrm{~km} / \mathrm{h}$, obtaining a saving of $9.67 \%$, with the performance of $1.55 \mathrm{~km} / \mathrm{L}$, compared to the $1.4 \mathrm{~km} / \mathrm{L}$ of the truck operator. The type of road considered in this route was good. The type of terrain is roughly shaped as: flat: $20 \%$, hilly: $50 \%$, and mountain: $30 \%$. However, the calculation considered a good road type and a hilly terrain type. Figure 6 displays the optimum driving speed of $75 \mathrm{~km} / \mathrm{h}$, which was obtained from the equality of the powers required and available. It was considered that on average, the driver drove steadily in 13th gear.

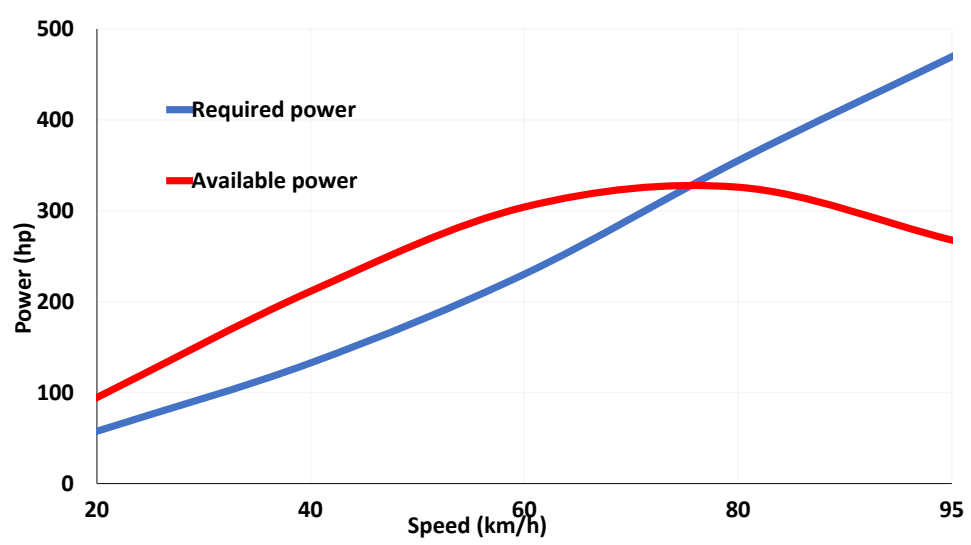

Figure 6. Route 2: Coyuca-Puebla to Lagunas-Oaxaca. Intersection of the curve of the available power of the 13th speed, and the curve of the required power of the hilly terrain and good road with $m=85,000 \mathrm{~kg}$.

The third route was from Tula-Hidalgo to Coyuca-Puebla. The run was carried out considering the speed calculated with the model of up to $120 \mathrm{~km} / \mathrm{h}$, obtaining a saving of $9.46 \%$, with the performance of $2.43 \mathrm{~km} / \mathrm{L}$, compared to the $2.20 \mathrm{~km} / \mathrm{L}$ of the truck operator. The type of road considered was good. The type of terrain is roughly shaped as: flat: $45 \%$, hilly terrain: $55 \%$. However, the calculation considered a good road type and hilly terrain type. Most of the terrain has no slopes, so fuel efficiency tends to be high. In Figure 7, the optimum driving speed of $120 \mathrm{~km} / \mathrm{h}$ is presented by obtaining from the equality of the powers required and available. It was considered that on average, the driver drove steadily in 14th gear. In the calculation, the time of hilly terrain and type of good road were assumed. 


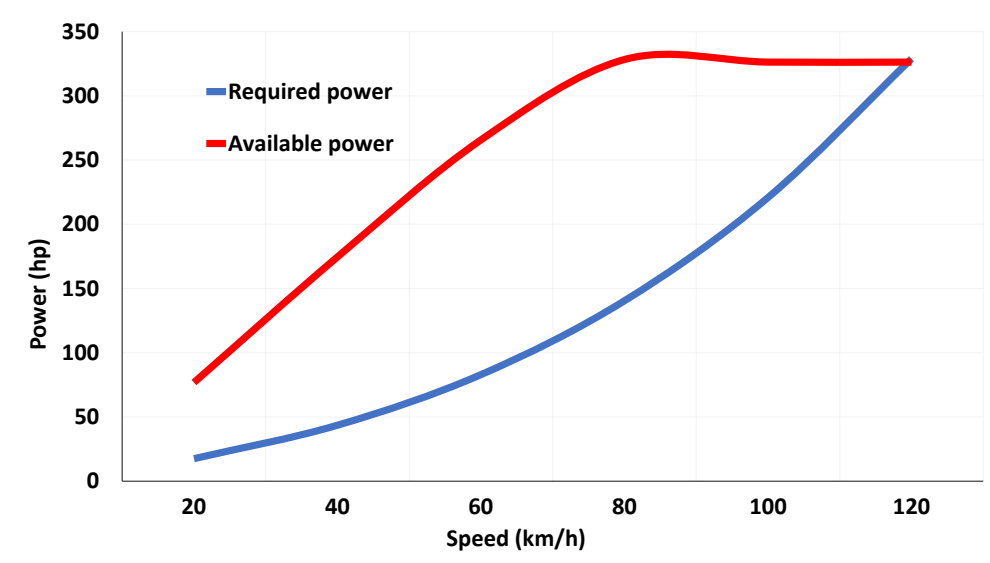

Figure 7. Route 3: Tula-Hidalgo to Coyuca-Puebla, Mexico. Intersection of the curve of the available power of the 14th speed and the curve of the required power of the hilly terrain and good road with $m=25,000 \mathrm{~kg}$.

The fourth route was from Jaltipan-Veracruz to Texcoco-Estado de Mexico. The run was carried out considering the speed calculated with the model of up to $65 \mathrm{~km} / \mathrm{h}$, obtaining a saving of $7.2 \%$, with the performance of $1.51 \mathrm{~km} / \mathrm{L}$, compared to the $1.4 \mathrm{~km} / \mathrm{L}$ of the truck operator.

The type of road considered was good. The type of terrain is roughly shaped as: flat: $60 \%$, hilly: $35 \%$, and mountain: $5 \%$. However, the calculation considered a good road type and a hilly terrain type. Most of the terrain has no slopes, so fuel efficiency tends to be high. In Figure 8, the performance of the model and the field work experiment is presented, where the optimum driving speed of $65 \mathrm{~km} / \mathrm{h}$ is obtained from the equality of the powers required and available. It was considered that on average, the driver drove steadily in 12 th gear. In the calculation, the time of hilly terrain and type of good road were assumed.

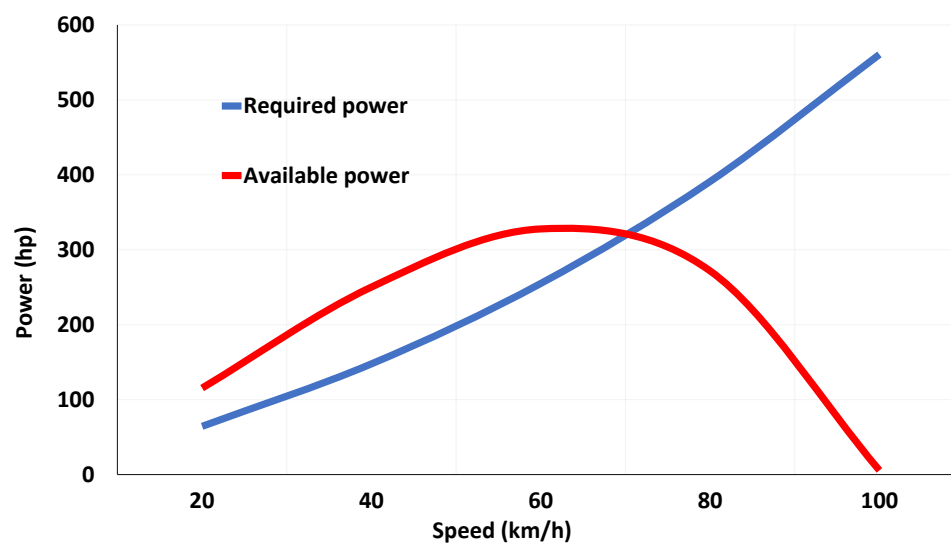

Figure 8. Route 4: Jaltipan-Veracruz to Texcoco-Estado de Mexico. Intersection of the curve of the available power of the 12th speed, and the curve of the required power of the hilly terrain and good road with $m=95,000 \mathrm{~kg}$.

The fifth route was from Texcoco-Estado de Mexico to Tula-Hidalgo. The run was carried out considering the speed calculated with the model of up to $7.2 \mathrm{~km} / \mathrm{h}$, obtaining a saving of $7.2 \%$, with the performance of $1.51 \mathrm{~km} / \mathrm{L}$, compared to the $1.4 \mathrm{~km} / \mathrm{L}$ of the truck operator. The type of road considered was good. The type of terrain is roughly shaped as: flat: $65 \%$, hilly: $35 \%$. However, the calculation considered a good road type and a hilly terrain type. Most of the terrain has no slopes, so fuel efficiency tends to be high. Figure 9 presents the optimum driving speed of $90 \mathrm{~km} / \mathrm{h}$ obtained from the equality of the powers required and available. It was considered that on average, the driver drove steadily in 12th gear. In the calculation, the time of hilly terrain and type of good road was assumed. 


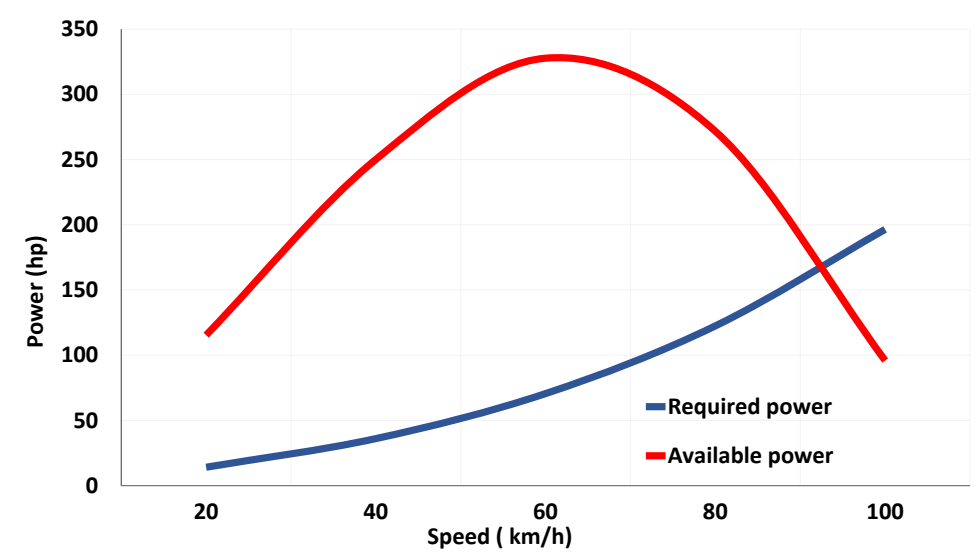

Figure 9. Route 5: Texcoco-Estado de Mexico to Tula-Hidalgo. Intersection of the curve of the available power of the 12th speed, and the curve of the required power of the hilly terrain and good road with $m=20,000 \mathrm{~kg}$.

The sixth route was from San Juan del Río-Queretaro to Coatzacoalcos-Veracruz. The run was carried out considering the speed calculated with the model of up to $85 \mathrm{~km} / \mathrm{h}$, obtaining a saving of $7.94 \%$, with the performance of $3.19 \mathrm{~km} / \mathrm{L}$, compared to the $2.78 \mathrm{~km} / \mathrm{L}$ of the truck operator. The type of road considered was good. The type of terrain is roughly shaped as: flat: $60 \%$, hilly: $35 \%$, and mountain: $5 \%$. However, the calculation considered a good road type and a hilly terrain type. Most of the terrain has no slopes, so fuel efficiency tends to be high. In Figure 10, the optimum driving speed of $85 \mathrm{~km} / \mathrm{h}$ is shown, obtained from the equality of the powers required and available. It was considered that on average, the driver drove steadily in 12th gear. In the calculation, the time of hilly terrain and type of good road were assumed.

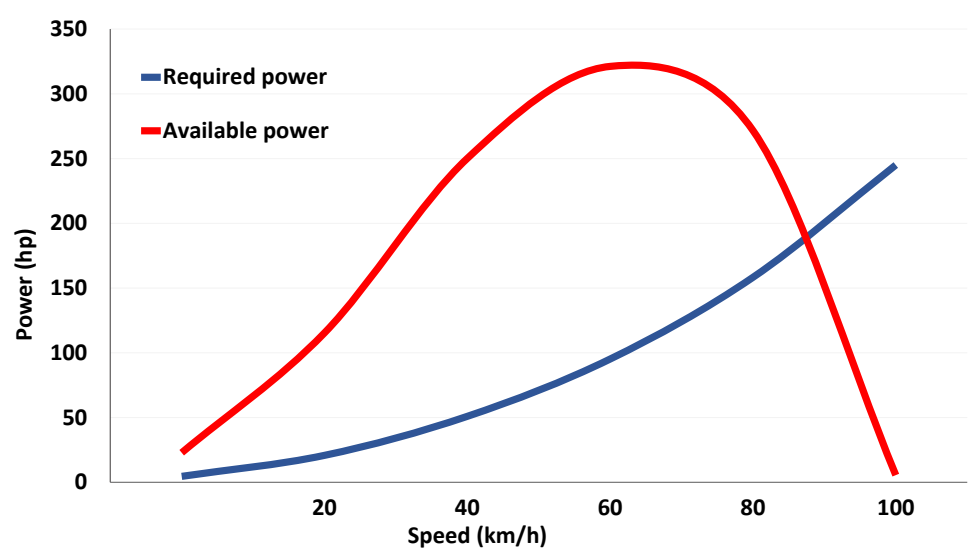

Figure 10. Route 6: San Juan del Río-Queretaro to Coatzacoalcos-Veracruz. Intersection of the curve of the available power of the 12th speed, and the curve of the required power of the hilly terrain and good road $m=30,000 \mathrm{~kg}$.

Finally, the seventh route was from Lagunas-Oaxaca to Jaltipan-Veracruz. The run was carried out considering the speed calculated with the model of up to $90 \mathrm{~km} / \mathrm{h}$, obtaining a saving of $12.86 \%$, with the performance of $3.38 \mathrm{~km} / \mathrm{L}$, compared to the $2.9 \mathrm{~km} / \mathrm{L}$ of the truck operator. The type of road considered was good. The type of terrain is roughly shaped as: flat: $25 \%$, hilly: $60 \%$, and mountain: $15 \%$. However, the calculation considered a good road type and a hilly terrain type. Figure 11 shows the performance of the model by obtaining the optimum driving speed of $90 \mathrm{~km} / \mathrm{h}$ according to the equality of the powers required and available. It was considered that on average, the driver drove steadily in 12 th gear. In the calculation, the time of hilly terrain and type of good road were assumed. 


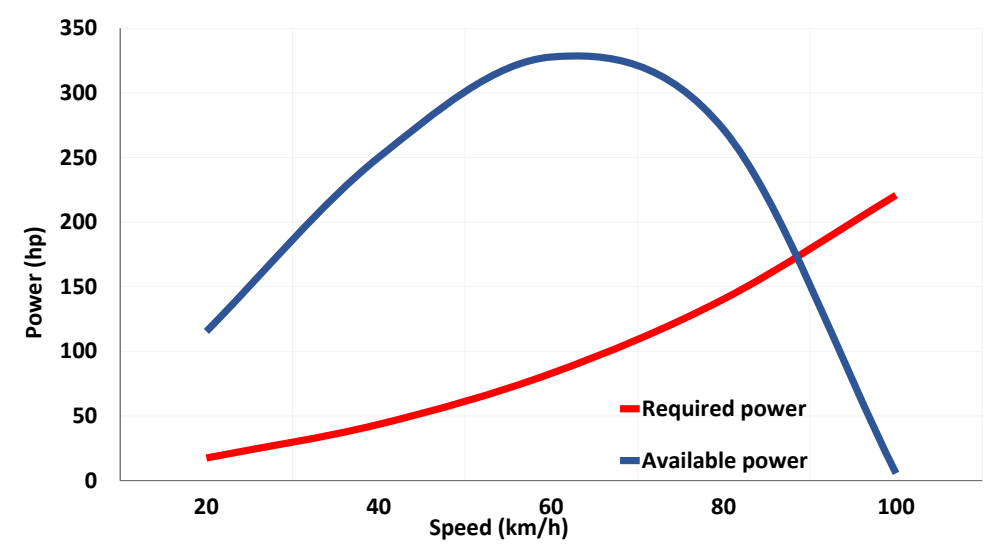

Figure 11. Route 7: Lagunas-Oaxaca to Jaltipan-Veracruz. Intersection of the curve of the available power of the 12th speed, and the curve of the required power of the hilly terrain and good road with $m=20,000 \mathrm{~kg}$.

Satisfactory results were obtained in the seven routes, observing an average of $10.09 \%$ savings.

\section{Discussion}

In Mexico, there are fourteen major highway corridors for the movement of cargo. The field work that was carried out is part of the branches of said corridors. The road characteristics of these regions are mostly good road and hilly terrain, which were considered in the calculations of the required force. Table 2 summarizes the characteristics of the type of terrain and type of road of the seven routes. The type of road and the percentages of type of terrain were calculated using the data provided by the Mexican Institute of Transportation.

Table 2. Characteristics of the routes used.

\begin{tabular}{|c|c|c|}
\hline Route & Origin to Destination & Terrain \\
\hline 1 & $\begin{array}{c}\text { Nuevo Laredo-Tamahulipas to } \\
\text { Querétaro-Querétaro }\end{array}$ & $\begin{array}{c}\text { Flat land: } 60 \% \text {; hilly terrain: } 30 \% \text {; } \\
\text { mountain: } 10 \%\end{array}$ \\
\hline 2 & Coyuca-Puebla to Lagunas-Oaxaca & $\begin{array}{c}\text { Flat land: } 20 \% \text {; hilly terrain: } 50 \% \text {; } \\
\text { mountain: } 30 \%\end{array}$ \\
\hline 3 & Tula-Hidalgo to Coyuca-Puebla & $\begin{array}{c}\text { Flat land: } 45 \% \text {; hilly terrain: } 55 \% \text {; } \\
\text { mountain: } 0 \%\end{array}$ \\
\hline 4 & $\begin{array}{c}\text { Jaltipan-Veracruz to Texcoco-Estado de } \\
\text { Mexico }\end{array}$ & $\begin{array}{c}\text { Flat land: } 60 \% \text {; hilly terrain: } 35 \% \text {; } \\
\text { mountain: } 5 \%\end{array}$ \\
\hline 5 & $\begin{array}{c}\text { Texcoco-Estado de Mexico to } \\
\text { Tula-Hidalgo }\end{array}$ & $\begin{array}{c}\text { Flat land: } 65 \% \text {; hilly terrain: } 35 \% \text {; } \\
\text { mountain: } 0 \%\end{array}$ \\
\hline 6 & $\begin{array}{l}\text { San Juan del Río-Querétaro to } \\
\text { Coatzacoalcos-Veracruz }\end{array}$ & $\begin{array}{c}\text { Flat land: } 60 \% \text {; hilly terrain: } 35 \% \text {; } \\
\text { mountain: } 5 \%\end{array}$ \\
\hline 7 & Lagunas-Oaxaca to Jaltipán-Veracruz & $\begin{array}{c}\text { Flat land: } 25 \% \text {; hilly terrain: } 60 \% \text {; } \\
\text { mountain: } 15 \%\end{array}$ \\
\hline
\end{tabular}

Table 3 shows the results of the field work. As can be seen in the seven routes, there are significant savings that if multiplied by the number of times the operator repeats the route, the company could save significant amounts of money. 
Table 3. Results of fieldwork.

\begin{tabular}{|c|c|c|c|c|c|c|c|c|}
\hline Route & Origin-Destination & Model (km/L) & Field Work (km/L) & Distance (km) & Save (\%) & Unit & Load & $\begin{array}{c}\text { Calculated } \\
\text { Maximum } \\
\text { Speed } \\
(\mathbf{k m} / \mathbf{h})\end{array}$ \\
\hline 1 & $\begin{array}{c}\text { Nuevo } \\
\text { Laredo-Tamahulipas } \\
\text { to Querétaro- } \\
\text { Querétaro }\end{array}$ & 2.87 & 2.6 & 914 & 7.14 & T3S2 & Empty & 85 \\
\hline 2 & $\begin{array}{l}\text { Coyuca-Puebla to } \\
\text { Lagunas-Oaxaca }\end{array}$ & 1.55 & 1.4 & 713 & 9.67 & T3S2R4 & Full & 75 \\
\hline 3 & $\begin{array}{l}\text { Tula-Hidalgo to } \\
\text { Coyuca-Puebla }\end{array}$ & 2.43 & 2.2 & 254 & 9.46 & T3S2R4 & Empty & 120 \\
\hline 4 & $\begin{array}{l}\text { Jaltipan-Veracruz, to } \\
\text { Texcoco, Estado de } \\
\text { Mexico }\end{array}$ & 1.51 & 1.4 & 560 & 7.2 & T3S2R4 & Full & 65 \\
\hline 5 & $\begin{array}{c}\text { Texcoco Estado de } \\
\text { Mexico to } \\
\text { Tula-Hidalgo }\end{array}$ & 3.83 & 3.2 & 94 & 16.44 & T3S2R4 & Empty & 90 \\
\hline 6 & $\begin{array}{c}\text { San Juan del Río, } \\
\text { Querétaro to } \\
\text { Coatazacoalcos } \\
\text { Veracruz }\end{array}$ & 3.19 & 2.78 & 398 & 7.94 & T3S2 & Full & 85 \\
\hline 7 & $\begin{array}{c}\text { Lagunas, } \\
\text { Oaxaca-Jaltipan, } \\
\text { Veracruz }\end{array}$ & 3.38 & 2.9 & 158 & 12.86 & T3S2R4 & Empty & 90 \\
\hline \multicolumn{9}{|c|}{ Average savings percentage: $10.09 \%$} \\
\hline
\end{tabular}

Finally, the difference obtained in terms of the type of driving of the seven routes according to the model and the driver is displayed in Figure 12. The average saving of $10.09 \%$ of the seven routes was obtained considering the characteristics of the highway according to the most significant highway corridors in Mexico. The application of the presented methodology shows significant savings in transport companies, the decrease in oil consumption, and the increase in the life of the tires and the engine. Driving the unit at the optimum speed does not force the unit and, in addition, significantly reduces accidents on the roads, also reducing polluting $\mathrm{CO}_{2}$ emissions by lowering diesel consumption. The automation of the presented method is left for future work so that in real time, the operator can see, during his journey, the speed on a display at which he must drive according to the type of terrain and type of road during the journey.

Although multiple works are related to improving performance or reducing emissions, this work presents two key characteristics that distinguish it from the actual investigations. The first characteristic is that the proposed system is not invasive. Any installation is required since the proposed method is embedded and portable, without changes in the vehicle or required fuel. On the other hand, and unlike typical eco-driving systems, this work considers the state of the road and the state of the vehicle for the calculation of the optimal speed and not only the revolutions of the engine. These characteristics are contrasted in Table 4. 
Table 4. Comparison of similar works in yield optimization or emissions reduction.

\begin{tabular}{cccccc}
\hline & \multicolumn{5}{c}{ Characteristics Considered } \\
\cline { 2 - 6 } Work & Not Invasive & Vehicle Variables & Road Variables & Load & Alternative Fuel \\
\hline Our Work & $\mathrm{x}$ & $\mathrm{x}$ & $\mathrm{x}$ & $\mathrm{x}$ & - \\
{$[8]$} & $\mathrm{x}$ & $\mathrm{x}$ & - & - & $\mathrm{x}$ \\
{$[9]$} & $\mathrm{x}$ & $\mathrm{x}$ & - & - & $\mathrm{x}$ \\
{$[10]$} & $\mathrm{x}$ & $\mathrm{x}$ & - & - & $\mathrm{x}$ \\
{$[11]$} & $\mathrm{x}$ & $\mathrm{x}$ & - & - & $\mathrm{x}$ \\
{$[12]$} & $\mathrm{x}$ & $\mathrm{x}$ & - & - & $\mathrm{x}$ \\
{$[13]$} & $\mathrm{x}$ & $\mathrm{x}$ & - & - & $\mathrm{x}$ \\
{$[14]$} & $\mathrm{x}$ & $\mathrm{x}$ & - & - & - \\
{$[16]$} & - & & & \\
\hline
\end{tabular}

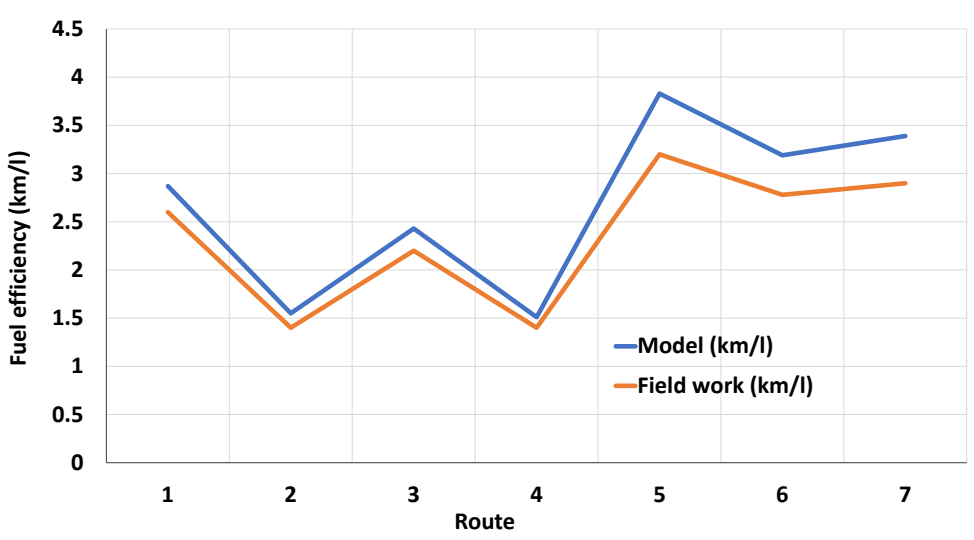

Figure 12. Fuel efficiency comparison: mathematical model vs. field work.

\section{Conclusions}

This article presented a novel mathematical model to calculate the speed maximum operating capacity of a land transport unit of load. Seven routes of transport companies and the intersections of the available power curve, with the curve of the power required for each particular route, were considered to perform the study. For each intersection, the maximum speed of driving was also determined as a result of the equality between the power available and required power. The savings in percentage of each route when driving at the maximum calculated speed were presented. From the results obtained, the drivers who observed better fuel efficiency and significant savings percentages were the routes: Lagunas, Oaxaca-Jaltipan, and Veracruz, with $25 \%$ flat terrain, $60 \%$ hillock, and $15 \%$ mountain, along with regular road type. The weight was $20,000 \mathrm{~kg}$ and the saving was $12.86 \%$, at a speed of $90(\mathrm{~km} / \mathrm{h})$. The other route with the best performance was that of Texcoco, State of Mexico-Tula, Hidalgo, with $65 \%$ flat terrain and 35\% hillocks, without mountainous terrain, and a regular type of highway. The weight was 20,000 kg and the saving was $16.44 \%$. As can be seen in the seven routes, there are significant savings that if multiplied by the number of times the operator repeats the route, the company could save significant amounts of money. It was verified in person that the transport unit has been operated according to the maximum speed calculated by the model. On average, savings of fuel were above $10 \%$. It was demonstrated that in operating the cargo land transport unit according to the particularity of each truck and the characteristics of each path, benefits are obtained for the economic transport companies. The proposed methodology ensures the maximum speed of driving and its corresponding fuel efficiency $(\mathrm{km} / \mathrm{L})$ as a tailored suit for each type of truck and route. The implementation of the methodology considered the type of good road and type of hill terrain, for the seven routes, since these routes are branches of the fourteen most important highway corridors in Mexico, which on average maintain good road and hill type terrain. The proposed model works, 
yielding significant savings for the seven transport companies. The proposed methodology ensures the maximum speed of driving and its corresponding fuel efficiency $(\mathrm{km} / \mathrm{L})$ as a tailored suit for each type of truck and route. For future work, it is proposed to continue with the automation of the model by the design of a prototype and the implementation of the training of a computer, through a neural network, to predict the optimal driving speed and optimize the fuel consumption of the UTTC. The network will be fed with the variables of a mathematical algorithm that was created to calculate the maximum speed at which a transport unit must be operated and the optimization of fuel consumption.

Author Contributions: Conceptualization, M.T.-F.; Methodology, M.T.-F.; Writing-original draft preparation, M.T.-F.; Writing-review and editing, F.A.C.-V., J.M.Á.-A., A.F.-R., J.R.-R. and O.R.-A.; Supervision, F.A.C.-V., A.F.-R., J.R.-R., J.M.Á.-A. and O.R.-A. All authors have read and agreed to the published version of the manuscript.

Funding: This research received funding from CONACYT, UAQ, UPQ, and PRODEP.

Institutional Review Board Statement: Not applicable.

Informed Consent Statement: Not applicable.

Data Availability Statement: The data presented in this study are available on request from the corresponding author.

Acknowledgments: This research was done with the help of the Autonomous University of Queretaro UAQ and Politechnic University of Queretaro UPQ.

Conflicts of Interest: The authors declare no conflict of interest. The funders had no role in the design of the study; in the collection, analyses, or interpretation of data; in the writing of the manuscript, or in the decision to publish the results.

\section{Abbreviations}

The following abbreviations are used in the manuscript:

F1 Available force

M Engine torque

T Gear transmission ratio

$r \quad$ Engine performance

$M_{0} \quad$ Polynomial regression coefficient

$M_{1} \quad$ Polynomial regression coefficient

$M_{2} \quad$ Polynomial regression coefficient

$R \quad$ Revolutions per minute of the engine

F2 Tractive force available in tires

Faerod Aerodynamic drag force

Frod Rolling resistance force

Fpend Resistance force to slope

a Acceleration

$m \quad$ Mass of the truck

$C_{2} \quad$ Air density

$C_{d} \quad$ Aerodynamic coefficient

A Front area of the truck

$V \quad$ Speed

$C_{8} \quad$ Rolling static coefficient

$C_{v} \quad$ Rolling dynamic coefficient

$p \quad$ Rolling friction coefficient

$g \quad$ Gravity acceleration

$\alpha \quad$ Inclination angle

$P_{r} \quad$ Required power

$P_{a} \quad$ Available power

$C_{1} \quad$ Constant of mathematical calculation 


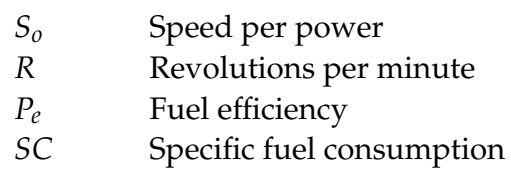

\section{References}

1. Lai, W.T. The effects of eco-driving motivation, knowledge and reward intervention on fuel efficiency. Transp. Res. Part Transp. Environ. 2015, 34, 155-160. [CrossRef]

2. Rakha, H.; Yue, H.; Dion, F. VT-Meso model framework for estimating hot-stabilized light-duty vehicle fuel consumption and emission rates. Can. J. Civ. Eng. 2011, 38, 1274-1286. [CrossRef]

3. Mane, A.; Djordjevic, B.; Ghosh, B. A data-driven framework for incentivising fuel-efficient driving behaviour in heavy-duty vehicles. Transp. Res. Part Transp. Environ. 2021, 95, 102845. [CrossRef]

4. Jiang, H.; Zhou, W.; Liu, C.; Zhang, G.; Hu, M. Safe and Ecological Speed Control for Heavy-Duty Vehicles on Long-Steep Downhill and Sharp-Curved Roads. Sustainability 2020, 12, 6813. [CrossRef]

5. Ahmed, M.M.; Ghasemzadeh, A. The impacts of heavy rain on speed and headway Behaviors: An investigation using the SHRP2 naturalistic driving study data. Transp. Res. Part C Emerg. Technol. 2018, 91, 371-384. [CrossRef]

6. Held, M.; Flärdh, O.; Mårtensson, J. Optimal Speed Control of a Heavy-Duty Vehicle in Urban Driving. IEEE Trans. Intell. Transp. Syst. 2019, 20, 1562-1573. [CrossRef]

7. Fulop, M.; Gubán, M.; Kovács, G.; Avornicului, M. Economic development based on a mathematical model: An optimal solution method for the fuel supply of international road transport activity. Energies 2021, 14, 2963. [CrossRef]

8. Gürbüz, H.; Demirtürk, S. Investigation of Dual-Fuel Combustion by Different Port Injection Fuels (Neat Ethanol and E85) in a DE95 Diesel/Ethanol Blend Fueled Compression Ignition Engine. J. Energy Resour. Technol. 2020, 142, 122306, [CrossRef]

9. Raman, L.A.; Deepanraj, B.; Rajakumar, S.; Sivasubramanian, V. Experimental investigation on performance, combustion and emission analysis of a direct injection diesel engine fuelled with rapeseed oil biodiesel. Fuel 2019, 246, 69-74. [CrossRef]

10. Khan, T.M.Y.; Soudagar, M.E.M.; Khandal, S.V.; Javed, S.; Mokashi, I.; Baig, M.A.A.; Ismail, K.A.; Elfasakhany, A. Performance of Common Rail Direct Injection (CRDi) Engine Using Ceiba Pentandra Biodiesel and Hydrogen Fuel Combination. Energies 2021, 14, 7142. [CrossRef]

11. Vinayagam, N.K.; Hoang, A.T.; Solomon, J.M.; Subramaniam, M.; Balasubramanian, D.; EL-Seesy, A.I.; Nguyen, X.P. Smart control strategy for effective hydrocarbon and carbon monoxide emission reduction on a conventional diesel engine using the pooled impact of pre-and post-combustion techniques. J. Clean. Prod. 2021, 306, 127310. [CrossRef]

12. Nayak, S.K.; Hoang, A.T.; Nižetić, S.; Nguyen, X.P.; Le, T.H. Effects of advanced injection timing and inducted gaseous fuel on performance, combustion and emission characteristics of a diesel engine operated in dual-fuel mode. Fuel 2022, 310, 122232. [CrossRef]

13. Bui, V.G.; Bui, T.M.T.; Hoang, A.T.; Nižetić, S.; Nguyen Thi, T.X.; Vo, A.V. Hydrogen-Enriched Biogas Premixed Charge Combustion and Emissions in Direct Injection and Indirect Injection Diesel Dual Fueled Engines: A Comparative Study. J. Energy Resour. Technol. 2021, 143, 120907, [CrossRef]

14. Tucki, K. A Computer Tool for Modelling $\mathrm{CO}_{2}$ Emissions in Driving Tests for Vehicles with Diesel Engines. Energies 2021, 14, 266 [CrossRef]

15. Mandal, A.; Cho, H.; Chauhan, B.S. ANN Prediction of Performance and Emissions of CI Engine Using Biogas Flow Variation. Energies 2021, 14, 2910. [CrossRef]

16. Groelke, B.; Borek, J.; Earnhardt, C.; Vermillion, C. Design and Performance Analysis of a Cascaded Model Predictive Controller and Command Governor for Fuel-Efficient Control of Heavy-Duty Trucks. J. Dyn. Syst. Meas. Control. 2021, 143, 061009. [CrossRef]

17. Huang, Y.; Ng, E.C.; Zhou, J.L.; Surawski, N.C.; Chan, E.F.; Hong, G. Eco-driving technology for sustainable road transport: A review. Renew. Sustain. Energy Rev. 2018, 93, 596-609. [CrossRef]

18. Chen, D.; Yan, X.; Liu, X.; Li, S.; Wang, L.; Tian, X. A Multiscale-Grid-Based Stacked Bidirectional GRU Neural Network Model for Predicting Traffic Speeds of Urban Expressways. IEEE Access 2021, 9, 1321-1337. [CrossRef]

19. Kiray, V.; Orhan, M.; Chijioke, J. Significant increase in fuel efficiency of diesel generators with lithium-ion batteries documented by economic analysis. Energies 2021, 14, 6904. [CrossRef]

20. Díaz, G.; Montecinos, D.; Nicolis, O.; Peralta, B. Recurrent Neural Networks applied to Forecasting of Speed of Freight Transport in Dense Areas of Santiago, Chile. In Proceedings of the 2019 IEEE CHILEAN Conference on Electrical, Electronics Engineering, Information and Communication Technologies (CHILECON), Santiago, Chile, 13-27 November 2019; pp. 1-7. [CrossRef]

21. Tišljarić, L.; Carić, T.; Erdelić, T.; Erdelić, M. Traffic State Estimation Using Speed Profiles and Convolutional Neural Networks. In Proceedings of the 2020 43rd International Convention on Information, Communication and Electronic Technology (MIPRO), Opatija, Croatia, 28 September-2 October 2020; pp. 1813-1818. [CrossRef]

22. David, B.S.L. Road freight transport in Mexico: Production and employment. Análisis Económico 2020, 35, 147-172.

23. Kuşkapan, E.; Çodur, M.Y.; Atalay, A. Speed violation analysis of heavy vehicles on highways using spatial analysis and machine learning algorithms. Accid. Anal. Prev. 2021, 155, 106098. [CrossRef] [PubMed] 
24. Secretariat of Communications and Transportation. NOM-012-SCT-2-2017. 2017. Available online: https://www.mexlaws.com/ SCT/NOM-012-SCT-2-2017.htm (accessed on 2 November 2021).

25. Torres Falcón, M.d.C.P.L.G. Application of chebyshev's theorem for estimating $\mathrm{CO}_{2}$ emissions due to over loading of heavy duty diesel trucks. Interciencia 2014, 39, 228-233.

26. Fitch, J. Motor Truck Engineering Handbook; Premiere Series Bks; Society of Automotive Engineers (SAE) International: Warrendale, PA, USA, 1994.

27. Arriaga, P.G.A. International Index of Roughness. Application on the Net Mexico Highway; Technical Report 108; Mexican Institute of Transportation: Mexico City, Mexico, 1998.

28. Torres, M. Construction of a Congruence Test by Extending the Chi-Square Test to Validate Theoretical Models. Ph.D. Thesis, Research Center in Applied Science and Advanced Technology, National Polytechnic Institute (IPN), Mexico City, Mexico, 2015.

29. Caterpillar. Caterpillar C-15 Engine Torque Curves. 2016. Available online: https://www.pon-cat.com/application/files/8515/4 227/6939/C15_ACERT_-18396631-004.pdf (accessed on 31 January 2021).

30. Corporation, D.D. Detroit DD15 Engine Torque Curves. 2007. Available online: https://atlanticdda.com/wp-content/uploads/ 2018/02/dd15-brochure.pdf (accessed on 31 January 2021).

31. Arroyo Osorno, J.A.; Aguerrebere Salido, R. Estado Superficial y Costos de Operación en Carreteras; IMT: Queretaro, Mexico, 2002.

32. Ávila, R.; Alarcón, J. Cálculo de los costos de operación vehicular en la carretera Cuitzeo-Puruándiro-Zináparo y su impacto en los usuarios. Cienc. Nicolaita $N^{o}$ 2006, 45, 85-96. 